\title{
Social roles among recruits in Switzerland: Do social roles relate to alcohol use and does role change have an impact?
}

\author{
Sandra Kuntsche ${ }^{\mathrm{a}, *}$, Mariana Astudillo ${ }^{\mathrm{a}}$, Gerhard Gmel ${ }^{\mathrm{a}, \mathrm{b}}$ \\ addiction Switzerland Research Institute, Lausanne, Switzerland \\ ${ }^{\mathrm{b}}$ Alcohol Treatment Centre, Lausanne University Hospital CHUV, Lausanne, Switzerland
}

\section{H I G H L I G H T S}

- Over time the number of young men living with a partner and being employed increased.

- No such change was found for parenthood.

- Living with a partner resulted in lower alcohol use at follow-up.

- Stable role situations related to lower alcohol use at follow-up.

\section{A R T I C L E I N F O}

\section{Article history:}

Received 20 February 2015

Received in revised form 4 December 2015

Accepted 14 December 2015

Available online 17 December 2015

\section{Keywords:}

Social roles

Maturing out

Men

Alcohol

\begin{abstract}
A B S T R A C T
Introduction: Young men are likely to report high levels of alcohol use. Previous studies found a reduction in alcohol use when adopting adult social roles. This study examines the frequency of parenthood, partnership and stable employment among young men in Switzerland. It tests whether the alcohol use of those with adult social roles differs from those without and whether changes in social roles relate to changes in alcohol use. Methods: Data was available from 5025 men (20.0 years) at baseline (August 2010 to November 2011) and 15 months later. Changes in social roles and their impact on alcohol use were examined in multiple regression models. Results: At baseline, $15.8 \%$ had a job and $4.9 \%$ a stable partner, and $1.5 \%$ had a child or were expecting one (30.5\%, $6.1 \%$ and $2.2 \%$ at follow-up). Having a partner was associated with a significant decrease in annual frequency of drinking and weekly risky single-occasion drinking (RSOD) at follow-up. A higher number of social roles at follow-up was associated with a significant decrease in weekly RSOD. Apart from a significant decrease in weekly RSOD among those remaining in a stable partnership, role development was not found to have significant effects on alcohol use between baseline and follow-up.

Conclusions: In Switzerland, an early engagement in permanent social roles is uncommon. Nevertheless, holding single or multiple social roles was commonly associated with reduced alcohol use, although not always significantly so. In western European countries, the engagement in adult social roles is postponed to later ages.
\end{abstract}

(c) 2015 Published by Elsevier Ltd.

\section{Introduction}

Social roles are based on enduring and stable relationships with others and therefore determine the individual's position within a given society by providing behavioural guidance and defining their identity (e.g. McCall \& Simmons, 1996). Consequently, many studies found a relationship between social roles and health behaviour such as substance use (e.g. Bachman et al., 2002; Galea, Nandi, \& Vlahov, 2004). Based on the assumptions of the role accumulation theory, holding social roles structures a person's daily life through meaningful activities related to the fulfilment of these roles and therefore results in

\footnotetext{
* Corresponding author at: Addiction Switzerland Research Institute, Av. Louis Ruchonnet 14, P.O. Box 870, 1001 Lausanne, Switzerland.

E-mail address: skuntsche@addictionsuisse.ch (S. Kuntsche).
}

beneficial health effects (Aneshensel, Frerichs, \& Clark, 1981; Hong \& Seltzer, 1995). Correspondingly, a recent study in 10 industrialised countries found that holding multiple social roles was associated with lower alcohol use, especially among men (Kuntsche, Knibbe, \& Gmel, 2009). The present study examines the frequency of parenthood, partnership and stable employment among young Swiss men; it tests whether the alcohol use of those with social roles differs from those without and whether changes in social roles relate to changes in alcohol use among those concerned.

Young men in particular are likely to report high levels of alcohol use (E. Kuntsche \& Gmel, 2013). Whereas the percentage of daily drinkers is rather low (below 2\%) in age groups under 25 and increases thereafter, risky single-occasion drinking (RSOD, also called binge drinking) peaks among 20 to 24-year-olds (Gmel, Notari, Georges, \& Wicki, 2012). Previous analyses using a sample of young men similar to the sample in 
the present study produced comparable results: $75.5 \%$ of those drinking reported at least monthly RSOD and $69.3 \%$ of their total weekly alcohol volume was consumed through RSOD (Gmel, Gaume, Faouzi, Kulling, \& Daeppen, 2008).

Previous studies in the USA found evidence that among young adults, entering a stable work position or living in a steady relationship may reduce a formerly high alcohol use to lower levels (Labouvie, 1996; Moffitt, 1993). Also, becoming a parent has been associated with reduced alcohol use (Bachman, Wadsworth, O'Malley, Schulenberg, \& Johnston, 1997; Labouvie, 1996). This decline was considered by some as a "maturing out" of problematic alcohol use (Johnstone, Leino, Ager, Ferrer, \& Fillmore, 1996). The adoption of role-related responsibilities and duties (Bachman et al., 2002) or role incompatibility as well as the increase in social control were considered as possible explanatory factors. However, due to differences in drinking cultures and the late engagement in permanent social roles, it is unknown to what degree results can be transferred to Europe.

In recent years the engagement in adult social roles seems to have shifted to later decades. In Switzerland, age at first marriage increased by five years between 1971 and 2013 (men $=31.9$ years, women $=$ 29.6 years, Federal Statistical Office (FSO), 2013). It is argued that reasons such as spending a longer time in education followed by a delayed entrance into the labour market, less traditional gender roles, birth planning using highly efficient contraception methods and a tendency to postpone marriage and children to later in life after having settled and made a career may explain the rise in age at first marriage and at the birth of the first child. In consequence, fewer women under 30 years of age and more women above 35 give birth in many western European countries (OECD, 2011). In Switzerland, data on the mean age at the birth of their first child is only available for married women; it increased by five years between 1970 (25.3 years) and 2012 (30.4 years: Federal Statistical Office (FSO), 2013).

The relevance of social roles for alcohol use has been shown for both genders and cross-culturally (S. Kuntsche et al., 2006; S. Kuntsche et al., 2009; Kuntsche, Knibbe, Kuntsche, \& Gmel, 2011) among adults older than 25 years, but - to the best of our knowledge - there are no studies on younger age groups. Younger age groups may be of particular importance as alcohol use is commonly high and social roles begin to emerge. Therefore, the present study examines the frequency of parenthood, partnership and regular occupation among young men in Switzerland. It also tests whether the alcohol use of those with social roles differs from that of those without and whether changes in social roles relate to changes in alcohol use among those concerned. In addition, as the engagement in social roles is limited in young men in Switzerland, the study does not focus on role combinations but instead on the number of social roles held and its impact on alcohol use (S. Kuntsche et al., 2006; S. Kuntsche et al., 2009; S. Kuntsche et al., 2011).

\section{Method}

The sampling of young men was carried out within the mandatory army recruitment system to which all Swiss men must present themselves in the year of their 19th birthday. Their eligibility for military or civil service is determined at conscription centres. In total, 13,245 young men present between August 2010 and November 2011 at three of the six national conscription centres in Switzerland (covering 21 of the 26 cantons) were asked to participate in the study; 7563 gave their informed written consent. Confidentiality was ensured for all participants, and the army environment was used only for enrolment purposes. Participation was independent of military or civil service. Questionnaires were sent to private addresses and the army was completely blinded about responses at baseline and follow-up. Ethical approval was obtained from the Ethics Committee for Clinical Research of the Lausanne University Medical School (research protocol 15/07).

During enrolment at the conscription centres, a short five-minute questionnaire containing sections on demography and alcohol, tobacco, and cannabis use was given to all recruits and answered by $94 \%$ of them. It was strictly confidential for those who did not provide informed consent. This questionnaire was used to compare consenters with nonconsenters (Studer, Mohler-Kuo, et al., 2013) and participants with those who gave written consent but did not return the questionnaires sent to their home addresses (silent refusal, Studer, Baggio, et al., 2013). Given the large sample size, there were some differences between consenters and non-consenters, but these differences were generally small and went in different directions. For example, nonconsenters who drank alcohol were slightly more often heavy alcohol consumers, but at the same time there were more abstainers among the non-consenters (Studer, Mohler-Kuo, et al., 2013).

Data from 5990 men was obtained at baseline $(t 1 ; 79.2 \%$ of those with consent). About 15 months after the first measurement, participants were re-contacted for a second measurement (t2) and 5223 (87.2\%) also responded at follow-up. The high response rate at follow-up was achieved through intense panel care, e.g. by sending birthday cards with small birthday presents between baseline and follow-up or through personal contact with those who did not respond within three weeks after an automatic reminder was sent out. The latter received what were known as encouraging telephone calls. The aim of these was to encourage nonrespondents to resume their involvement in the study by establishing direct person-to-person contact. The calls were based on motivational interviewing techniques (Miller \& Rose, 2009) - one of the research institutions involved in the study (the Alcohol Treatment Centre in Lausanne) has particular strengths in providing brief motivational interviewing (Bertholet, Faouzi, Gmel, Gaume, \& Daeppen, 2010; Gaume, Gmel, Faouzi, \& Daeppen, 2009) and their experts trained interviewer staff.

At both time points, participants reported their alcohol use and provided information on their social roles. Respondents' age ranged from 18 to 28 with a mean age of $20.0(S D=1.23)$ at baseline. Further details of the survey and the sample were published elsewhere (Studer, Baggio, et al., 2013) and can also be found online (www.c-surf.ch).

\subsection{Measures}

\subsubsection{Social roles}

The present study focused on three social roles: being or becoming a parent (i.e. the partner being pregnant), having a stable partner and having a paid job. Given the present age range, it was impossible to distinguish in the analysis between marriage and co-habitation as this would have limited the number of respondents fulfilling this social role. The authors therefore decided to focus on partnership, using two categories of marital status (having a stable partner and being married) to create this indicator.

The role of employment was defined on the basis of the respondent's current professional status. Those with regular part-time or full-time work were coded as employed whereas those without a job, on an apprenticeship or in university education were coded as unemployed. Those in military or civil service were also coded as unemployed as military service in Switzerland includes 18 or 21 weeks of basic training and annual three-week refresher courses until a number of service days is reached. Although it is also possible to complete one's military service over a continuous 300-day period, a maximum of $15 \%$ of recruits per year choose this option. Civil service is usually spread over several years with 390 days of community service in total.

All three measures on social roles are dichotomous (yes $=1 \mathrm{vs}$. no $=0$ ) and were available at both time points. A count measure (number of social roles) was then derived on the basis of these three measures. A previous study showed that the number of social roles an individual held was a good indicator of alcohol use for both genders in most countries (S. Kuntsche et al., 2009).

\subsubsection{Change in social roles}

Besides the fact of holding a social role or not, a measure for role change between the two measurements was developed using the 
following categories: role not endorsed (neither at $t 1$ nor $\mathrm{t} 2$ : 0 ), loss of the role (role present at $\mathrm{t} 1$ but not at $\mathrm{t} 2: \mathrm{1}$ ), gain of the role (not at $\mathrm{t} 1$ but at $\mathrm{t} 2$ : 2 ) and stable role (role present at $t 1$ and $t 2: 3$ ). In addition to the measures of change for each individual role, a summary measure for all three roles was developed. In the majority of cases, role loss in the context of parenthood consisted of reporting a pregnant partner at $\mathrm{t} 1$ but not reporting being a father at $\mathrm{t} 2(\mathrm{n}=35$ of 37$)$. The role loss in the remaining two cases is probably linked to the separation of couples as unmarried fathers do not automatically have childcare responsibilities in Switzerland.

\subsubsection{Alcohol use}

Four alcohol measures were examined: (1) Risky single-occasion drinking ( $R S O D$, also called binge drinking) was measured with the question "About how often do you drink six or more units of alcohol on a single occasion?". The standard drink size in Switzerland is about $10 \mathrm{~g}$ of pure ethanol per drink and a measure of six drinks or more therefore corresponds to about $60 \mathrm{~g}$ of pure ethanol, which is equivalent to the $5+$ RSOD measures used in countries with drink sizes of about $12 \mathrm{~g}$ of pure ethanol. A picture provided examples of standard drink sizes of beer, wine, long drinks, alcopops and spirits. Response options ranged from "never" to "daily or almost daily". The measure was recoded to become dichotomous, distinguishing "at least weekly RSOD" (1) from "no weekly RSOD" (0). (2) The usual number of alcoholic drinks per drinking day was measured using the question "How many standard drinks do you drink on average on days when you drink alcohol?" with an open response format. (3) Usual drinking frequency was measured with the question "How many days a week do you usually drink alcohol?", with response categories ranging from "never" to "seven days a week", and this data was subsequently recoded into annual drinking frequencies. (4) Lastly, a generic quantity-frequency measure was derived by multiplying measures (2) and (3). All alcohol measures refer to a timeframe of 12 months prior to the survey.

\subsection{Analytical plan}

Two cases with missing information on age were excluded, as were those with missing values on social roles $(n=198)$. The final sample includes 5025 individuals participating at baseline and follow-up and providing data on all social roles considered. Changes in social roles and differences in alcohol use were analysed first, using unadjusted regression models (ordinary regression for means and logistic regressions for proportions) with time of measurement $(\mathrm{t} 1=0, \mathrm{t} 2=1)$ as independent variables and social roles and alcohol use variables (RSOD, annual drinking frequency, usual quantity and generic volume) as dependent variables (results presented in Table 1).

In a second step, multiple ordinary regression models were used to test the relationship between holding single or multiple social roles at t2 and usual quantity of drinking, annual drinking frequency and volume of drinking at follow-up. A multiple logistic regression model was used to examine the impact on weekly RSOD (results presented in Table 2).

In a third and final step, the relationship between role changes (not endorsed, gain, stable, loss) for each role separately and the number of roles and alcohol use at $\mathrm{t} 2$ was examined in either multiple ordinary or logistic regressions (results presented in Table 3). All analyses in the second and third step were adjusted for age and alcohol use at baseline ( $\mathrm{t} 1$ ). As significance relies heavily on sample size, the present study also considers the consistency of the findings (Rothman, 2002) across different social roles and alcohol measures as an indicator for the relationship between alcohol use and social roles.

\section{Results}

At baseline the mean age was 20.0 years. The abstention rate was about $7 \%$ and did not change significantly between $\mathrm{t} 1$ and $\mathrm{t} 2$. Alcohol use remained stable over time. The only significant change was found
Table 1

Means and proportions of alcohol measures and social roles by time of measurement.

\begin{tabular}{lrlrll}
\hline & \multicolumn{3}{c}{ Baseline (t1) } & & \\
\hline Mean (SD) & & & & & \\
Age in years & 20.0 & $(1.20)$ & & & \\
Annual drinking frequency & 80.4 & $(72.59)$ & 86.7 & $(74.23)$ & $* *$ \\
Generic drinking volume & 7.2 & $(11.91)$ & 7.5 & $(9.22)$ & n.s. \\
Usual drinking quantity & 4.0 & $(3.79)$ & 4.0 & $(3.49)$ & n.s. \\
Proportion (SD) & & & & & \\
Abstainer & 7.2 & $(0.26)$ & 7.4 & $(0.26)$ & n.s. \\
Weekly RSOD & 22.1 & $(0.42)$ & 20.3 & $(0.40)$ & n.s. \\
Children (yes) & 1.5 & $(0.12)$ & 2.2 & $(0.44)$ & n.s. \\
Partner (yes) & 4.9 & $(0.22)$ & 6.1 & $(0.72)$ & $*$ \\
Occupation (yes) & 15.8 & $(0.37)$ & 30.5 & $(1.38)$ & $* * *$ \\
\hline
\end{tabular}

Note: n.s. not significant; ${ }^{*} \mathrm{p}<0.05 ;{ }^{* *} \mathrm{p}<0.01 ;{ }^{* * *} \mathrm{p}<0.001$ statistical tests based on regression models predicting alcohol use or social role by time of measurement, see Method section.

in mean annual drinking frequency, which increased between the baseline (80.4) and follow-up (86.7; see Table 1).

The frequency of living in a partnership ( $\mathrm{t} 1: 4.9 \%$; $\mathrm{t}$ : $6.1 \%)$ and being employed ( $\mathrm{t} 1: 15.8 \%$; $\mathrm{t} 2: 30.5 \%$ ) increased significantly between the two measurements, whereas for parenthood no significant difference was found (t1: $1.5 \%$; $t 2: 2.2 \%$ ). Living in a stable partnership or being or becoming a parent remained a relatively rarely endorsed role.

Regarding the relationship between social roles and alcohol use in baseline adjustment models (Table 2), having a partner at $\mathrm{t} 2$ was associated with significantly lower annual drinking frequencies and weekly RSOD. For example, men living in a partnership reported more than seven $(-7.16)$ drinking days less than men without partners. Neither parenthood nor having a job had a significant impact on alcohol use. Overall, a higher number of social roles was associated with a significantly lower prevalence of weekly RSOD (see Table 2).

Holding a social role and an increased number of social roles in most cases resulted in lower alcohol use, although not always significantly so. The only exceptions to the general protective effect of social roles related either to being employed (usual quantity and annual drinking frequency) or having a child (weekly RSOD); none of these associations was significant.

The associations between alcohol use at $\mathrm{t} 2$ and social role changes between baseline and follow-up are given in Table 3. A significantly lower prevalence of weekly RSOD was found for those living in a stable partnership at both measurements. Although other social roles or role changes between $\mathrm{t} 1$ and $\mathrm{t} 2$ generally did not attain statistical significance, stable role situations, i.e. having the same role at both measurements, almost systematically resulted in lower alcohol use (with the exception of annual frequency of drinking and employment or number of roles). In contrast, loss or gain of social role did not have a significant relationship with alcohol use, nor did it result in a consistent pattern of increase or decrease across the different alcohol measures.

\section{Discussion}

Despite a few significant associations between alcohol use and holding a single role, namely being in a stable partnership, or between holding multiple roles and weekly RSOD, the present study did not find a major impact of social roles on alcohol use among young men. However, in the rare cases where a significant relationship with alcohol use was found, holding social roles had a protective effect.

The most beneficial and consistent effect on alcohol use within this age group was related to living in a stable partnership, with the effects mainly consisting of lower drinking frequency and lower prevalence of RSOD. Being or becoming a parent also commonly showed beneficial effects but the prevalence of being a father at this age is probably simply too low to become significant. Being employed may not have a beneficial effect at this age, possibly because at younger ages this firstly increases the affordability of alcohol use. At younger ages, therefore, an 
Table 2

Baseline adjustment ${ }^{1}$ regression models of social roles at $\mathrm{t} 2$ on alcohol use variables ( $\mathrm{t} 2$ ), unstandardized coefficients (B) and standard error (SE).

\begin{tabular}{|c|c|c|c|c|c|c|c|c|c|c|c|c|}
\hline & \multicolumn{3}{|c|}{ Usual drinking quantity } & \multicolumn{3}{|c|}{ Annual drinking frequency } & \multicolumn{3}{|c|}{ Generic drinking volume } & \multicolumn{3}{|c|}{$\mathrm{RSOD}^{2}$} \\
\hline & B & SE & $\mathrm{p}$ & B & SE & $\mathrm{p}$ & B & SE & $\mathrm{p}$ & $\mathrm{OR}$ & SE & $\mathrm{p}$ \\
\hline Children (yes) & -.171 & .300 & .568 & -2.95 & 5.59 & .598 & -.790 & .807 & .328 & 1.05 & 0.29 & .860 \\
\hline Partnership (yes) & -.196 & .183 & .286 & -7.16 & 3.41 & $.036^{*}$ & -.882 & .493 & .074 & 0.65 & 0.19 & $.022^{*}$ \\
\hline Employment (yes) & .013 & .095 & .893 & 0.89 & 1.76 & .616 & -.151 & .255 & .553 & 0.85 & 0.09 & .067 \\
\hline Number of roles & -.038 & .078 & .624 & -0.89 & 1.45 & .538 & -.314 & .209 & .134 & 0.83 & 0.08 & $.014^{*}$ \\
\hline
\end{tabular}

* $\mathrm{p}<0.05$

1 Analysis adjusted for age and corresponding alcohol use variables at $\mathrm{t} 1$.

2 Dichotomous measure (1) at least weekly, (0) less frequent or abstainer.

increase in the number of roles held may not yet sufficiently translate into an overall beneficial effect, due to accumulating effects with different signs of impact for different social roles.

The present study found no consistency in the impact of losing or gaining social roles on alcohol use. This is surprising as studies in older age groups have found a relationship between role gain/loss and alcohol use (Neve, Lemmens, \& Drop, 2000; Temple et al., 1991). Besides the fact that social roles in this young age group are not yet established and are only just beginning to emerge, role changes are at least temporarily a normative phenomenon. In addition, holding social roles at this age may even increase the opportunities to engage in alcohol use as employment not only offers more structure as a role but also makes more money available to be spent on alcohol, for example.

In Switzerland, permanent engagement in adult social roles in early adulthood seems rather uncommon, as demonstrated by the low proportion of respondents living in a partnership or having children. This is in line with other western European countries, where a postponement of the engagement in adult social roles to later than early adulthood was found (OECD, 2011). Arnett $(1998,2000)$ described this as "emerging adulthood", a period characterised by extended exploration and postponement of adult markers. Thus, a delay in traditional roles can be seen not only as possible but even as necessary given recent sociocultural developments and economic factors. As a consequence, holding a social role at 20 years of age could therefore be viewed as a behaviour that is "outside the norm". On the one hand, early adoption of social roles, such as having a stable partnership, may be associated with differences in the general value system, higher levels of religiosity, differences in socioeconomic or cultural background and a rural setting, and these differences in values may not only influence role engagement but could also be linked to lower alcohol use in general. Studies found that the adoption of social roles was facilitated by certain psychological capacities, such as flexibility, social competence and agency (Blatterer, 2007; Chung, Little, \& Steinberg, 2005; Côté \& Bynner, 2008). Results of previous studies further suggested that those with a university or college education took on fewer social roles than blue collar workers (e.g. Reitzle, 2006) or did so at older ages (e.g. Thornton, Axinn, \& Teachman, 1995). On the other hand, it may also be possible that having a child or living with a partner at such an early age - bearing in mind that nowadays this behaviour is usually shifted to the $30 \mathrm{~s}$ in Switzerland - may be linked with underlying problems or more demanding living situations, such as low levels of education or lower socioeconomic status per se, and could therefore be related to higher alcohol use. Our results seem to support the first interpretation more than the second. Future research may focus on individual characteristics of those engaging in adult social roles at an early age compared with those who do not.

The present study has a number of limitations. Firstly, the analyses are based on self-reported measures of alcohol consumption, which underestimates the actual alcohol use (E. Kuntsche \& Labhart, 2012; Livingston \& Callinan, 2015; Rehm et al., 2010; Stockwell, Zhao, \& Macdonald, 2014). Secondly, only young men of approximately 20 years of age were included, and our results cannot be generalised beyond this population. Thirdly, since cohort participation was facultative, a non-response bias may exist, albeit a small one (Studer, Baggio, et al., 2013). Fourthly, the follow-up measurement was carried out 15 months later, a time interval which could be too short to cover major role changes as engagement in social roles is postponed to later ages than two or three decades ago (OECD, 2011). Lastly, possible external factors have not yet been sufficiently examined. The individual characteristics of those engaging in social roles at an early age need to be studied in

Table 3

Baseline adjustment ${ }^{1}$ regression models of the impact of social role changes on alcohol use variables, unstandardized coefficients (B) and standard error (SE).

\begin{tabular}{|c|c|c|c|c|c|c|c|c|c|c|c|c|}
\hline & \multicolumn{3}{|c|}{ Usual drinking quantity } & \multicolumn{3}{|c|}{ Annual drinking frequency } & \multicolumn{3}{|c|}{ Generic drinking volume } & \multicolumn{3}{|l|}{$\mathrm{RSOD}^{2}$} \\
\hline & $\mathrm{B}$ & SE & $\mathrm{p}$ & B & SE & $\mathrm{p}$ & $\mathrm{B}$ & SE & $\mathrm{p}$ & OR & SE & $\mathrm{p}$ \\
\hline \multicolumn{13}{|c|}{ Children (reference: not endorsed $n=4879$ ) } \\
\hline Loss $(n=37)$ & .604 & .507 & .234 & -17.945 & 9.440 & .057 & -1.193 & 1.364 & .382 & 1.208 & .470 & .688 \\
\hline Gain $(n=69)$ & .243 & .372 & .514 & -3.297 & 6.933 & .634 & -.147 & 1.002 & .883 & 1.246 & .336 & .512 \\
\hline Stable $(\mathrm{n}=40)$ & -.885 & .493 & .073 & -2.964 & 9.182 & .747 & -1.973 & 1.326 & .137 & .687 & .579 & .517 \\
\hline \multicolumn{13}{|c|}{ Partnership (reference: not endorsed $n=4553$ ) } \\
\hline Loss $(n=163)$ & .027 & .245 & .912 & 2.493 & 4.566 & .585 & .151 & .659 & .819 & .911 & .226 & .681 \\
\hline Gain $(\mathrm{n}=227)$ & -.028 & .210 & .894 & -5.774 & 3.911 & .140 & -.664 & .565 & .240 & .747 & .207 & .158 \\
\hline Stable $(\mathrm{n}=82)$ & -.674 & .347 & .052 & -10.779 & 6.461 & .095 & -1.493 & .940 & .112 & .328 & .494 & $.024^{*}$ \\
\hline \multicolumn{13}{|c|}{ Employment (reference: not endorsed $n=3127$ ) } \\
\hline $\operatorname{Loss}(n=363)$ & .130 & .171 & .449 & -3.204 & 3.202 & .317 & 0.430 & .462 & .352 & 1.182 & .149 & .263 \\
\hline Gain $(n=1102)$ & .051 & .108 & .636 & .457 & 2.007 & .820 & -.074 & .290 & .797 & .873 & .101 & .176 \\
\hline Stable $(n=433)$ & -.037 & .160 & .819 & .717 & 2.984 & .810 & -.181 & .431 & .674 & .851 & .154 & .297 \\
\hline \multicolumn{13}{|c|}{ Number of roles (reference: not endorsed $n=2833$ ) } \\
\hline Loss $(n=541)$ & .128 & .145 & .378 & -2.445 & 2.711 & .367 & .299 & .391 & .444 & 1.118 & .128 & .384 \\
\hline Gain $(n=1243)$ & .021 & .105 & .843 & .198 & 1.955 & .919 & -.084 & .282 & .766 & .881 & .098 & .196 \\
\hline Stable $(\mathrm{n}=408)$ & -.086 & .165 & .603 & .731 & 3.081 & .812 & -.197 & .445 & 658 & .833 & .160 & .253 \\
\hline
\end{tabular}

$* \mathrm{p}<0.05$

1 Models adjusted for age and corresponding baseline alcohol use variables.

2 Dichotomous measure (1) at least weekly, (0) less frequent or abstainer. 
more detail, something the present study could not do due to the small number of cases involving parenthood or stable partnerships.

To conclude, in Switzerland, 20-year-old men rarely engage in social roles. Those who do engage in single social roles, namely having a partner, report a lower frequency of (heavy) alcohol use compared to those without a partner. Similar protective effects were found for multiple social roles on weekly RSOD. Gaining or losing a social role over time was not associated with a significant change in alcohol use, whereas a stable role situation (i.e. keeping a stable partner) was associated with a decreasing rate of weekly RSOD.

\section{Acknowledgements}

The present study was funded by the Swiss National Science Foundation (contract 33CSCO-122679/1).

\section{References}

Aneshensel, C. S., Frerichs, R. R., \& Clark, V. A. (1981). Family roles and sex differences in depression. Journal of Health and Social Behavior, 22(4), 379-393.

Arnett, J. J. (1998). Learning to stand alone: The contemporary American transition to adulthood in cultural and historical context. Human Development, 41(5-6), 295-315.

Arnett, J. J. (2000). Emerging adulthood. A theory of development from the late teens through the twenties. American Psychologist, 55(5), 469-480.

Bachman, J. G., O'Malley, H. M., Schulenberg, J. E., Johnston, L. D., Bryant, A. L., \& Merline, A. C. (2002). The decline of substance use in young adulthood: Changes in social activities, roles, and beliefs. Mahwah, NJ: Lawrence Erlbaum.

Bachman, J. G., Wadsworth, K. N., O'Malley, P. M., Schulenberg, J., \& Johnston, L. D. (1997) Marriage, divorce, and parenthood during the transition to young adulthood: Impact on drug use and abuse. In J. Schulenberg, J. L. Maggs, \& K. Hurrelmann (Eds.), Health risks and developmental transitions during adolescence (pp. 246-279). Cambridge: Cambridge University Press.

Bertholet, N., Faouzi, M., Gmel, G., Gaume, J., \& Daeppen, J. -B. (2010). Change talk sequence during brief motivational intervention, towards or away from drinking. Addiction, 105(12), 2106-2112. http://dx.doi.org/10.1111/j.1360-0443.2010.03081.x.

Blatterer, H. (2007). Contemporary adulthood reconceptualizing an uncontested category. Current Sociology, 55(6), 771-792.

Chung, H. L., Little, M., \& Steinberg, L. (2005). The transition to adulthood for adolescents in the juvenile justice system: A developmental perspective. In D. W. Osgood, E. M. Foster, C. Flanagan, \& G. R. Ruth (Eds.), On your own without a net: The transition to adulthood for vulnerable populations. University of Chicago Press.

Côté, J., \& Bynner, J. M. (2008). Changes in the transition to adulthood in the UK and Canada: The role of structure and agency in emerging adulthood. Journal of Youth Studies, 11(3), 251-268. http://dx.doi.org/10.1080/13676260801946464.

Federal Statistical Office (FSO) (2013). Components of population change - Data, indicators: Average age at first marriage. Retrieved 28.09.2015, from http://www.bfs. admin.ch/bfs/portal/en/index/themen/01/06/blank/key/05/04.html.

Galea, S., Nandi, A., \& Vlahov, D. (2004). The social epidemiology of substance use. Epidemiologic Reviews, 26, 36-52.

Gaume, J., Gmel, G., Faouzi, M., \& Daeppen, J. -B. (2009). Counselor skill influences outcomes of brief motivational interventions. Journal of Substance Abuse Treatment, 37(2), 151-159. http://dx.doi.org/10.1016/j.jsat.2008.12.001.

Gmel, G. Gaume, J., Faouzi, M., Kulling J. -P. \& Daeppen, J. -B. (2008). Who drinks most of the total alcohol in young men - Risky single occasion drinking as normative behaviour. Alcohol and Alcoholism, 43(6), 692-697. http://dx.doi.org/10.1093/alcalc/ agn070.

Gmel, G., Notari, L., Georges, A., \& Wicki, M. (2012). Alkohol, Suchtmonitoring Schweiz/ Jahresbericht - Daten 2011. Bern / Lausanne: Bundesamt für Gesundheit/Sucht Schweiz.
Hong, J., \& Seltzer, M. M. (1995). The psychological consequences of multiple roles: The nonnormative case. Journal of Health and Social Behavior, 36(4), 386-398.

Johnstone, B. M., Leino, E. V., Ager, C. R., Ferrer, H. P., \& Fillmore, K. M. (1996). Determinants of life-course variation in the frequency of alcohol consumption: Metaanalysis of studies from the collaborative alcohol-related longitudinal project. Journal of Studies on Alcohol, 57(5), 494-506.

Kuntsche, E., \& Gmel, G. (2013). Alcohol consumption in late adolescence and early adulthood - Where is the problem? Swiss Medical Weekly, 143, w13826.

Kuntsche, E., \& Labhart, F. (2012). Investigating the drinking patterns of young people over the course of the evening at weekends. Drug and Alcohol Dependence, 124(3), 319-324. http://dx.doi.org/10.1016/j.drugalcdep.2012.02.001.

Kuntsche, S., Gmel, G., Knibbe, R. A., Kuendig, H., Bloomfield, K., Kramer, S., \& Grittner, U. (2006). Gender and cultural differences in the association between family roles, social stratification, and alcohol use: A European cross-cultural analysis. Alcohol and Alcoholism, 41(Suppl. 1), i37-i46. http://dx.doi.org/10.1093/alcalc/agl074.

Kuntsche, S., Knibbe, R. A., \& Gmel, G. (2009). Social roles and alcohol consumption: A study of 10 industrialised countries. Social Science and Medicine, 68(7), 1263-1270. http://dx.doi.org/10.1016/j.socscimed.2009.01.018.

Kuntsche, S., Knibbe, R. A., Kuntsche, E., \& Gmel, G. (2011). Housewife or working mum-Each to her own? The relevance of societal factors in the association between social roles and alcohol use among mothers in 16 industrialized countries. Addiction, 106(11), 1925-1932. http://dx.doi.org/10.1111/j.1360-0443.2011.03507.x.

Labouvie, E. W. (1996). Maturing out of substance use: Selection and self-correction. Journal of Drug Issues, 26(2), 457-476.

Livingston, M., \& Callinan, S. (2015). Underreporting in alcohol surveys: Whose drinking is underestimated? Journal of Studies on Alcohol and Drugs, 76(1), 158-164.

McCall, G., \& Simmons, R. (1996). Identities and interactions. New York: Free Press.

Miller, W. R., \& Rose, G. S. (2009). Toward a theory of motivational interviewing. American Psychologist, 64(6), 527-537. http://dx.doi.org/10.1037/a0016830.

Moffitt, T. E. (1993). Adolescence-limited and life-course-persistent antisocial behavior: A developmental taxonomy. Psychological Review, 100(4), 674-701.

Neve, R. J. M., Lemmens, P. H., \& Drop, M. J. (2000). Changes in alcohol use and drinking problems in relation to role transitions in different stages of the life course. Substance Abuse, 21(3), 163-178. http://dx.doi.org/10.1080/08897070009511430.

OECD (2011). Families are changing. In OECD (Ed.), Doing better for families (pp. 17-53). OECD Publishing.

Rehm, J., Kehoe, T., Gmel, G., Jr., Stinson, F. S., Grant, B. F., \& Gmel, G. (2010). Statistical modeling of volume of alcohol exposure for epidemiological studies of population health: The US example. Population Health Metrics, 8, 3. http://dx.doi.org/10.1186/ 1478-7954-8-3.

Reitzle, M. (2006). The connections between adulthood transitions and the selfperception of being adult in the changing contexts of East and West Germany. European Psychologist, 11(1), 25.

Rothman, K. J. (2002). Epidemiology - An introduction. Oxford: Oxford University Press.

Stockwell, T., Zhao, J., \& Macdonald, S. (2014). Who under-reports their alcohol consumption in telephone surveys and by how much? An application of the 'yesterday method' in a national Canadian substance use survey. Addiction, 109(10), 1657-1666. http://dx.doi.org/10.1111/add.12609.

Studer, J., Baggio, S., Mohler-Kuo, M., Dermota, P., Gaume, J., Bertholet, N., ... Gmel, G. (2013). Examining non-response bias in substance use research - Are late respondents proxies for non-respondents? Drug and Alcohol Dependence, 132(1-2), 316-323. http://dx.doi.org/10.1016/j.drugalcdep.2013.02.029.

Studer, J., Mohler-Kuo, M., Dermota, P., Gaume, J., Bertholet, N., Eidenbenz, C., ... Gmel, G. (2013). Need for informed consent in substance use studies - Harm of bias? Journal of Studies on Alcohol and Drugs, 74(6), 931-940.

Temple, M. T., Fillmore, K. M., Hartka, E., Johnstone, B. M., Leino, E. V., \& Motoyoshi, M. (1991). A meta-analysis of change in marital and employment status as predictors of alcohol consumption on a typical occasion. British Journal of Addiction, 86(10), $1269-1281$.

Thornton, A., Axinn, W. G., \& Teachman, J. D. (1995). The influence of school enrollment and accumulation on cohabitation and marriage in early adulthood. American Sociological Review, 60(5), 762-774. 